\title{
Isometric Strength Measures are Superior to the Timed Up and Go Test for Fall Prediction in Older Adults: Results from a Prospective Cohort Study
}

This article was published in the following Dove Press journal: Clinical Interventions in Aging

\author{
Pedro L Valenzuela' \\ Nicola A Maffiuletti ${ }^{2}$ \\ Hugo Saner ${ }^{3,4}$ \\ Narayan Schütz ${ }^{4}$ \\ Beatrice Rudin 5 \\ Tobias $\mathrm{Nef}\left(\mathbb{D}^{6}\right.$ \\ Prabitha Urwyler $\mathbb{D}^{4,6,7}$ \\ 'Department of Systems Biology, \\ University of Alcalá, Madrid, Spain; \\ ${ }^{2}$ Human Performance Lab, Schulthess \\ Clinic, Zurich, Switzerland; ${ }^{3}$ Institute for \\ Social and Preventive Medicine, \\ University of Bern, Bern, Switzerland; \\ ${ }^{4}$ Gerontechnology \& Rehabilitation \\ Group, University of Bern, Bern, \\ Switzerland; ${ }^{5}$ Höhere Fachschule Pflege, \\ Berufsbildungszentrum Olten, Olten, \\ Switzerland; ${ }^{6}$ ARTORG Center for \\ Biomedical Engineering Research, \\ University of Bern, Bern, Switzerland; \\ ${ }^{7}$ Department of Neurology, University \\ Neurorehabilitation Unit, University \\ Hospital Inselspital, Bern, Switzerland
}

Correspondence: Prabitha Urwyler University of Bern, ARTORG Center for Biomedical Engineering Research,

Murtenstrasse 50, Bern 3008, Switzerland

Tel +4I 3I 6327607

Email prabitha.urwyler@artorg.unibe.ch
Background: Isometric strength measures and timed up and go (TUG) tests are both recognized as valuable tools for fall prediction in older adults. However, results from direct comparison of these two tests are lacking. We aimed to assess the potential of isometric strength measures and the different modalities of the TUG test to detect individuals at risk of falling.

Methods: This is a prospective cohort study including 24 community-dwelling older adults $(\geq 65$ years, 19 females, $88 \pm 7$ years). Participants performed three variations of the TUG test (standard, counting and holding a full cup) and three isometric strength tests (handgrip, knee extension and hip flexion) at several time points (at baseline and every $\sim 6$ weeks) during a one-year follow-up. The association between these tests and the incidence of falls during the follow-up was assessed. Results: Twelve participants out of 24 participants experienced falls during the follow-up. Fallers showed a significantly lower handgrip strength $(-5.7 \mathrm{~kg}, 95 \%$ confidence interval: -10.4 to $-1.1, \mathrm{p}=0.019)$ and knee extension strength $(-4.9 \mathrm{~kg},-9.6$ to $-0.2, \mathrm{p}=0.042)$ at follow-up, while no significant differences were found for any TUG variation.

Conclusions: Handgrip and knee extension strength measures - particularly when assessed regularly over time - have the potential to serve as a simple and easy tool for detecting individuals at risk of falling as compared to functional mobility measures (ie, TUG test).

Keywords: functional assessment, geriatrics, elderly, physical performance, muscle strength, sarcopenia

\section{Plain Language Summary}

Optimizing screening tools to identify individuals at risk of falls should be a priority. Both isometric strength measures and timed up and go (TUG) tests are recognized as valuable tools for fall prediction in older adults, but results from direct comparison of these two tests are lacking. The present study shows that isometric strength measures of different muscle groups (ie, knee extensors and handgrip) significantly differentiated fallers from non-fallers during a 12-month follow-up regardless of potential confounding factors such as age, gender, body mass index, and previous history of falls. By contrast, although fallers did also present a worse performance than non-fallers in all TUG test modalities (ie, standard, while counting and while holding a full cup), these differences disappeared when adjusting for confounding factors. Isometric strength measures (particularly knee extension and handgrip) might therefore serve as a simple and more valid tool to detect individuals at risk of falling compared to functional mobility measures (ie, TUG test).

\section{Introduction}

Falls are a major concern for older adults and everyone involved. An estimated $30 \%$ of adults over 65 years of age fall at least once per year increasing to $50 \%$ for those over 
80 years of age. ${ }^{1,2}$ One-third of these falls lead to mild-tosevere injuries and in many cases require hospitalization, thereby imposing a substantial burden on health and social services. ${ }^{3,4}$ Moreover, falls are the largest cause of restricted activity among older adults, ${ }^{4}$ which further contributes to their functional decline. ${ }^{5}$ Thus, optimizing screening tools to identify individuals at risk of falls should be a priority. ${ }^{6}$

Apart from extrinsic risk factors (eg, slippery floor, poor lighting), a number of intrinsic factors have been associated to a higher risk of falls. ${ }^{7}$ These person-specific factors include non-modifiable characteristics such as age or gender; but also amenable factors such as physical performance. ${ }^{7}$ Thus, fall prevention programs should ideally be multifactorial, ${ }^{8}$ and the assessment of physical performance (eg, balance, muscle strength, or functional mobility) have been proposed as a cornerstone in the screening of individuals at high risk of falls. $^{6}$

The timed up and go (TUG) test, in which patients have to rise from a chair, walk 3 meters, turn around, walk back and sit down again, is one of the most popular tools for assessment of physical performance - specifically, of functional mobility - in older adults. ${ }^{9}$ This test is recommended as an assessment of sarcopenia ${ }^{10}$ and as a screening tool for fall risk by the American and British Geriatrics Societies. ${ }^{11}$ However, despite its popularity and some evidence supporting its usefulness, ${ }^{12,13}$ different systematic reviews and meta-analyses have questioned its actual validity. ${ }^{14-16}$

Muscle strength, an important determinant of physical performance which deteriorates with aging, ${ }^{17,18}$ can be easily assessed during isometric maximal voluntary contractions by means of portable dynamometers. ${ }^{19,20}$ Evidence suggests that fallers present an impaired isometric strength in multiple muscle groups compared to non-fallers. ${ }^{21-24}$ However, the superiority of strength tests over functional mobility tests (such as the TUG) for the identification of individuals at risk of falls remains poorly known.

In this context, the main purpose of this study was to analyze the validity of isometric strength measures including handgrip, knee extension and hip flexion strength in comparison with different modalities of TUG test for the identification of community-dwelling older adults at risk of falls during a one-year follow-up.

\section{Materials and Methods}

\section{Participants}

This is a substudy of the StrongAge Olten Cohort study whose primary aim was to assess the potential of passive infrared sensors with regard to physical activity quantification and to use the data as predictor for specific health issues. $^{25,26}$ Inclusion criteria were: age $>70$ years, the ability to live in a home or apartment, and live independently. Recruitment aimed to represent a naturalistic sample of single living, community-dwelling older adults in central Switzerland, irrespective of their cognitive status.

The study population consisted of 24 old and oldest-old seniors in similar and stable social and living conditions (see Table 1 for descriptive characteristics). Major comorbidities with some impact on physical performance during the study period were heart failure (New York Heart Association class I-II) in four patients, reasonably well-controlled type 2 diabetes in three patients and pulmonary emboli in two patients. No formal sample size estimation was performed a priori, but previous studies reported differences in lower limb strength (hip flexion) ${ }^{27}$ and TUG performance ${ }^{28}$ between fallers and non-fallers with effect sizes of 1.18-1.26, and thus a sample size of 18-20 might be considered enough to detect differences with a power $\geq 80 \%$ and a one-tailed $\alpha<0.05$ (G-Power version 3.1.9.2, Universität Düsseldorf, Germany).

The study was conducted based on the principles expressed in the Declaration of Helsinki and its protocol was approved by the responsible Ethics Committee of the canton Bern and the Ethics Committee of Northwestern and Central Switzerland (EKNZ) (KEK-ID: 2016-00406). All participants signed and provided written informed consent to participate in this study and permission to use their data for research and publications without restrictions.

\section{Study Design}

This study followed a prospective design and complies with the STROBE checklist for Observational Studies.

Level of independence and cognition was assessed at baseline using the Katz score ${ }^{29}$ and Montreal Cognitive Assessment (MOCA), ${ }^{30}$ respectively. Participants' functional mobility, isometric strength and incidence of falls were assessed at baseline and continuously every $\sim 6$ weeks during a one-year follow-up. All assessments were conducted at the participants' home, by the same researcher, and at approximately the same time of the day. The different assessments were randomized within each visit.

\section{Assessment of Physical Performance Functional Mobility}

Functional mobility was assessed using the TUG-standard, TUG-cognitive and TUG-motor tests. ${ }^{31}$ During TUGstandard, participants stood up from a chair, walked 3 meters, 
turned around, walked back to the chair, and sat down. During TUG-cognitive, participants performed the TUG standard task while counting backwards from a randomly selected number between 20 and 100. During TUG motor, participants performed the TUG-standard task while carrying a full cup of water. The time (in seconds) required to complete each test was recorded using a stopwatch.

\section{Isometric Strength}

Maximal voluntary isometric handgrip strength was assessed with a digital hand dynamometer (Jamar Plus+, Sammons Preston Rolyan, Chicago, USA) following available guidelines. ${ }^{19}$ Briefly, participants remained seated with their elbow flexed at $90^{\circ}$ and the forearm and wrist in a neutral position on the chair armrest. They performed three maximal trials with each hand and the highest value recorded during the six trials was retained. Maximal voluntary isometric strength of the hip flexors and knee extensors was measured with a hand-held dynamometer (Lafayette 01165, Lafayette Instrument Company, Lafayette, USA) according to the methodology described elsewhere. ${ }^{20}$ For both muscle groups, participants were seated with both hips and knees flexed at $90^{\circ}$. For the assessment of hip flexors, the dynamometer was placed on the anterior part of the thigh proximal to the knee joint, whereas for the knee extensors the dynamometer was placed on the anterior aspect of the shank, proximal to the ankle joint. Following the same protocol as with handgrip strength, participants performed three maximal trials for each muscle group and side, and the highest value of each muscle group was retained.

\section{Assessment of Falls}

According to the American and British Geriatrics Society falls prevention guidelines, ${ }^{11}$ a fall was defined as an unexpected event in which the participant came to rest on the ground, floor or lower level without known loss of consciousness. History of falls was assessed through personal interviews with the participants and their relatives. During follow-up, nursing students visited the seniors once or twice a week to record and document the incidence of falls by means of standardized questionnaires. Falls that occurred as a result of events such as heart attack, fainting or syncope were not included. Participants who sustained $\geq 1$ fall during the follow-up were considered "fallers".

\section{Statistical Analysis}

Differences between groups (ie, fallers vs non-fallers) at baseline were assessed using Student's unpaired t-tests. The association between physical performance tests and the incidence of falls during the follow-up was assessed by means of binary logistic regression analyses. Differences between fallers and non-fallers during the follow-up (presented together with $95 \%$ confidence intervals [CI]) were determined using linear-mixed modelling The physical tests (ie, functional mobility or isometric strength) were considered as the dependent variable, group (ie, fallers vs non-fallers) was set as a fixed factor, and subject was added as a random intercept. Analyses were adjusted for age, gender, body mass index, and previous falls history as fixed factors. All analyses were performed using the statistical software (SPSS version 23.0, IBM, Armonk) under a significance level of $\alpha=0.05$.

\section{Results}

Twelve participants fell at least once during the follow-up, resulting in a total of 20 falls. Of these, 4 falls were due to stumbling, and the remaining ones had no specified cause. Two participants died during the study approximately at month $\sim 5$ and $\sim 9$ of the follow-up, and thus could only be assessed 4 and 6 times, respectively. Both of them had a previous history of falls, and did also sustain a fall during the follow-up.

Fallers did not significantly differ from non-fallers in gender, independence, age or body mass index, but had lower MOCA scores (Table 1). Significant differences were found at baseline between fallers and non-fallers for TUG-standard and TUG-motor, but not for TUGcognitive. Inter-group differences were also observed for handgrip and knee strength, but not for hip strength (Table 1).

The association between baseline results for strength and TUG tests and the risk of falling is shown in Table 2. Non-adjusted analyses with baseline data showed that participants with a greater handgrip and knee extension strength had a lower risk of falling during the follow-up, whereas no significant results were found for the remaining measures. The same trend was observed in adjusted analyses, although these results did not reach statistical significance $(p=0.056$ and $p=0.070$ for handgrip and knee strength). Baseline MOCA scores were not significantly associated with the risk of falling in non-adjusted (odds 
Table I Baseline Characteristics of Study Participants

\begin{tabular}{|c|c|c|c|c|}
\hline Variable & All $(n=24)$ & Fallers $(n=12)$ & Non-Fallers $(n=12)$ & p-value \\
\hline Gender (n, \% female) & 19 (79\%) & $9(75 \%)$ & $10(83 \%)$ & 0.615 \\
\hline Age (years) & $88 \pm 7$ & $91 \pm 8$ & $86 \pm 6$ & 0.055 \\
\hline Body mass index $\left(\mathrm{kg} \mathrm{m}^{-2}\right)$ & $24.4 \pm 3.2$ & $23.3 \pm 3.5$ & $25.5 \pm 2.6$ & 0.083 \\
\hline Katz ADL score $[\max =6]$ & $5.7 \pm 0.7$ & $5.5 \pm 0.9$ & $5.8 \pm 0.4$ & 0.259 \\
\hline MOCA score $[\max =30]$ & $20.9 \pm 5.5$ & $18.5 \pm 5.7$ & $22.8 \pm 2.4$ & 0.033 \\
\hline Handgrip strength (kg) & $20.9 \pm 5.6$ & $17.7 \pm 4.9$ & $24.2 \pm 4.3$ & 0.002 \\
\hline Hip flexion strength (kg) & $15.5 \pm 5.2$ & $14.3 \pm 3.8$ & $16.8 \pm 6.2$ & 0.248 \\
\hline Knee extension strength $(\mathrm{kg})$ & $13.2 \pm 4.4$ & $10.8 \pm 3.4$ & $15.6 \pm 4.2$ & 0.006 \\
\hline TUG-standard (s) & $12.1 \pm 7.5$ & $15.2 \pm 8.3$ & $8.9 \pm 5.1$ & 0.038 \\
\hline TUG-cognitive (s) & $14.9 \pm 15.7$ & $20.0 \pm 20.7$ & $9.7 \pm 5.4$ & 0.110 \\
\hline TUG-motor (s) & $12.7 \pm 5.6$ & $15.0 \pm 4.6$ & $10.5 \pm 5.6$ & 0.049 \\
\hline
\end{tabular}

Notes: Values expressed as mean \pm SD (unless otherwise stated). The p-values refer to the differences between fallers and non-fallers. Significant $p$-values are highlighted in bold.

Abbreviations: ADL, activities of daily living; BMI, body mass index; MOCA, Montreal cognitive assessment; TUG, timed up and go.

Table 2 Associations Between Baseline Physical Performance Test Results and the Risk of Falling During the One-Year FollowUp

\begin{tabular}{|c|c|c|}
\hline Test & $\begin{array}{l}\text { Crude OR } \\
(95 \% \mathrm{Cl})\end{array}$ & $\begin{array}{l}\text { Adjusted OR } \\
(95 \% \mathrm{Cl})^{*}\end{array}$ \\
\hline Handgrip strength $(\mathrm{kg})$ & $\begin{array}{l}0.73(0.56,0.94) \\
\mathbf{p}=\mathbf{0 . 0 1 7}\end{array}$ & $\begin{array}{l}0.74(0.55,1.01) \\
P=0.056\end{array}$ \\
\hline Hip flexion strength $(\mathrm{kg})$ & $\begin{array}{l}0.90(0.74, I .08) \\
P=0.25 I\end{array}$ & $\begin{array}{l}0.91(0.74,1.13) \\
P=0.392\end{array}$ \\
\hline Knee extension strength $(\mathrm{kg})$ & $\begin{array}{l}0.74(0.57,0.95) \\
\mathbf{p}=\mathbf{0 . 0 1 6}\end{array}$ & $\begin{array}{l}0.77(0.58,1.02) \\
P=0.070\end{array}$ \\
\hline TUG-standard (s) & $\begin{array}{l}1.23(0.99, \quad I .52) \\
P=0.057\end{array}$ & $\begin{array}{l}I .19(0.94,1.5 \mathrm{I}) \\
P=0.14 \mathrm{I}\end{array}$ \\
\hline TUG-cognitive (s) & $\begin{array}{l}1.19(0.99, \quad I .43) \\
P=0.060\end{array}$ & $\begin{array}{l}\mathrm{I} .16(0.92, \mathrm{I} .45) \\
\mathrm{P}=0.210\end{array}$ \\
\hline TUG-motor (s) & $\begin{array}{l}1.19(0.99,1.44) \\
P=0.066\end{array}$ & $\begin{array}{l}1.18(0.93,1.50) \\
p=0.166\end{array}$ \\
\hline
\end{tabular}

Notes: Data are shown as odds ratio (OR), $95 \%$ confidence intervals $(\mathrm{Cl})$ and $\mathrm{p}$-values. Significant p-values are highlighted in bold. *Adjusted for gender, age, body mass index, and previous history of falls.

ratio: $0.77,95 \% \mathrm{CI}: 0.59$ to $1.01, \mathrm{p}=0.054)$ nor in adjusted analyses (odds ratio: $0.79,95 \% \mathrm{CI}: 0.57$ to $1.09, \mathrm{p}=0.157$ ).

The association between follow-up results and the risk of falling is shown in Table 3. Non-adjusted analyses showed an impaired performance in all TUG modalities and strength tests during the follow-up for fallers compared to non-fallers (Figure 1, Table 3). Isometric strength measures of knee extension and handgrip remained significantly different between fallers and non-fallers when adjusting for potential confounding factors (ie, age,
Table 3 Differences in Physical Performance Tests Between Fallers and Non-Fallers During the One-Year Follow-Up

\begin{tabular}{|c|c|c|}
\hline Test & $\begin{array}{l}\text { Crude Difference } \\
(95 \% \mathrm{Cl})\end{array}$ & $\begin{array}{l}\text { Adjusted Difference } \\
(95 \% \mathrm{Cl})^{*}\end{array}$ \\
\hline $\begin{array}{l}\text { Handgrip strength } \\
(\mathrm{kg})\end{array}$ & $\begin{array}{l}-7.01(-10.72,-3.31) \\
\mathbf{p}=\mathbf{0 . 0 0 1}\end{array}$ & $\begin{array}{l}-5.74(-10.41,-1.08) \\
\mathbf{p}=\mathbf{0 . 0 1 9}\end{array}$ \\
\hline $\begin{array}{l}\text { Hip flexion strength } \\
(\mathrm{kg})\end{array}$ & $\begin{array}{l}-4.22(-8.00,-0.43) \\
\mathbf{p}=\mathbf{0 . 0 3 1}\end{array}$ & $\begin{array}{l}-2.72(-6.98,1.54) \\
P=0.196\end{array}$ \\
\hline $\begin{array}{l}\text { Knee extension } \\
\text { strength }(\mathrm{kg})\end{array}$ & $\begin{array}{l}-7.11(-11.00,-3.22) \\
p=0.001\end{array}$ & $\begin{array}{l}-4.92(-9.62,-0.21) \\
\mathbf{p}=\mathbf{0 . 0 4 2}\end{array}$ \\
\hline TUG-standard (s) & $\begin{array}{l}9.23(1.63,16.82) \\
p=0.020\end{array}$ & $\begin{array}{l}7.23(-0.71,15.16) \\
P=0.072\end{array}$ \\
\hline TUG-cognitive (s) & $\begin{array}{l}13.30(2.93,23.66) \\
p=0.014\end{array}$ & $\begin{array}{l}9.62(-1.43,20.67) \\
P=0.084\end{array}$ \\
\hline TUG-motor (s) & $\begin{array}{l}8.53(1.73,15.32) \\
p=0.016\end{array}$ & $\begin{array}{l}4.56(-2.92,12.03) \\
p=0.216\end{array}$ \\
\hline
\end{tabular}

Notes: Data (estimate [95\% confidence intervals] and $p$-value) represent the difference between groups (ie, fallers vs non-fallers) during the follow-up. Significant $\mathrm{p}$-values are highlighted in bold. *Adjusted for gender, age, body mass index, and previous history of falls.

gender, body mass index, and previous falls history). By contrast, no between-group differences were found for isometric hip flexion nor for any of the TUG variations in adjusted analyses, although a non-significant trend was observed for both TUG-standard and -cognitive (Table 3).

\section{Discussion}

The main findings of this prospective study were that knee extensor and handgrip isometric strength assessed at baseline and particularly during a one-year follow-up period significantly differentiated fallers from non-fallers regardless of 

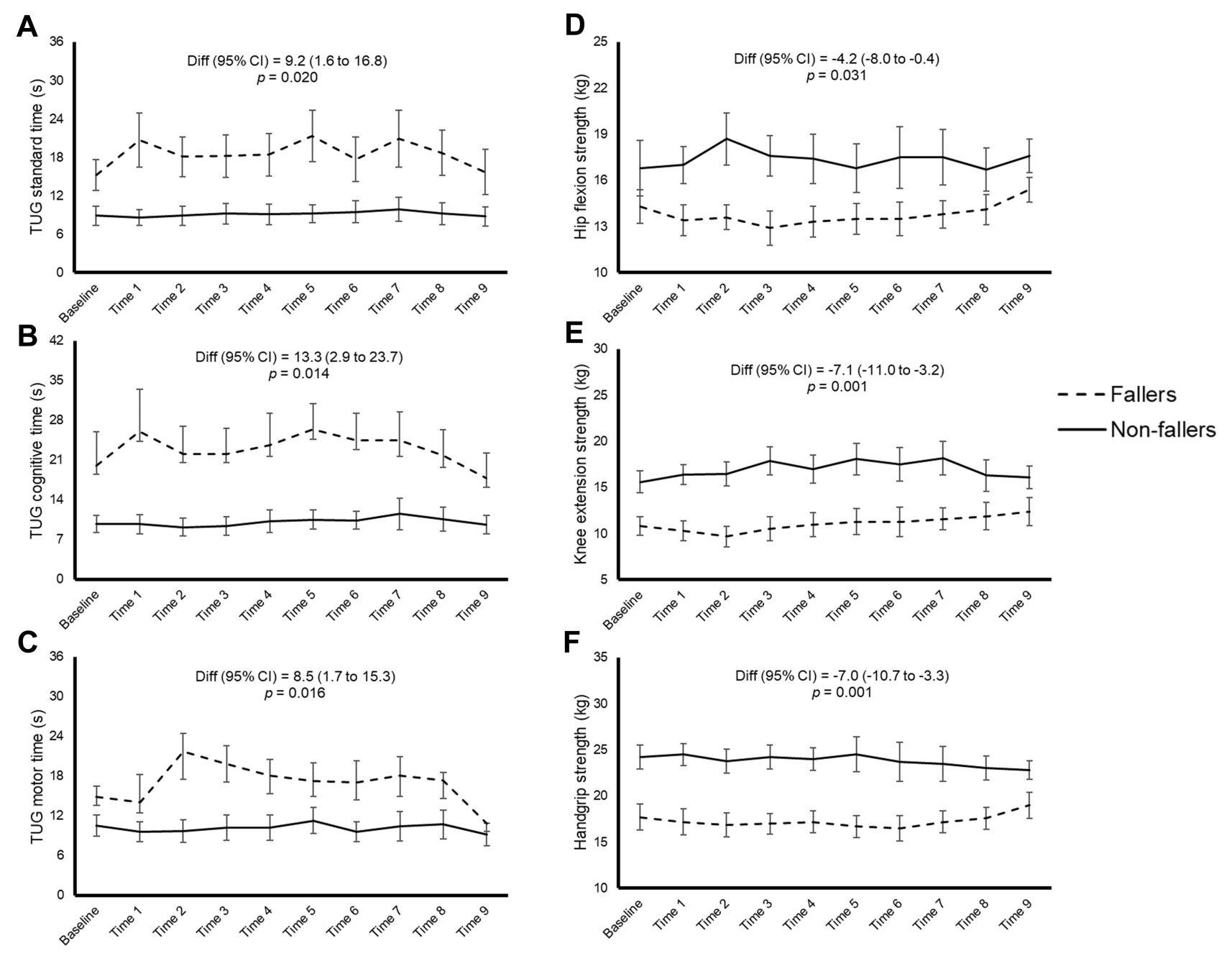

Figure I Functional mobility (A-C) and isometric strength (D-F) results in fallers and non-fallers during the one-year follow-up. Multiple imputation was performed to create the figures, as there were missing data $(<25 \%)$ at some time points. The crude difference (diff, expressed along with $95 \%$ confidence intervals [Cl]) corresponds to the average difference between groups, and was computed using linear mixed model analysis with no data imputation. Significant differences between groups were found for all tests.

potential confounding factors such as age, gender, body mass index, and previous history of falls. By contrast, differences between fallers and non-fallers in all TUG test modalities (ie, standard, count and motor) disappeared when adjusting for confounding factors, which supports isometric strength as a more sensitive screening measure than functional mobility. To the best of our knowledge, this is the first study comparing the validity of isometric strength and functional mobility measures for the identification of individuals at risk of falls in a homogenous population of oldest old living under similar circumstances.

The TUG test is one of the most widely used tests for falls prediction among older adults ${ }^{11}$ and its validity has already been studied. Shumway-Cook et $\mathrm{al}^{12}$ observed that the TUG test had a sensitivity and specificity of $87 \%$ to detect individuals prone to falls. However, in line with our findings, more recent evidence has called into question the validity of this tool. ${ }^{14-16}$ Some authors suggested that the inclusion of dual/cognitive TUG tasks (eg, counting back) might increase its validity for this purpose. ${ }^{31}$ Accordingly, the inclusion of additional TUG tasks increased its accuracy in identifying pre-frail individuals in some studies. ${ }^{32}$ However, other authors found similar sensitivity and specificity when comparing the three (standard, cognitive, motor) TUG modalities. ${ }^{12}$ Although the cognitive status of fallers was significantly lower than non-fallers at baseline, none of the TUG modalities considered in this study (including those with cognitive tasks) could discern fallers from non-fallers in adjusted analyses. Thus, the evidence supporting the validity of the TUG test with or without dual-tasks for the identification of individuals at risk of falls is at least inconclusive. 
On the other hand, the present study supports the validity of isometric knee extension and handgrip strength measures - particularly when assessed regularly over time - as a screening tool to detect individuals at risk of falling. Previous studies have reported that tests such as the "chair stand test, vertical jump test or leg press" are useful screening tools for lower limb strength and functionality which are often impaired in fallers compared to non-fallers. ${ }^{22,33}$ Isometric strength measures such as those implemented here have also been previously related to falls risk in older adults. Pijnappels et $\mathrm{al}^{22}$ observed that individuals who fell after gait perturbations presented the lowest isometric knee extension strength. In addition, Menant et $\mathrm{al}^{21}$ observed that low isometric knee extension strength was related to different health-related outcomes in the elderly (including balance, functional mobility and falls). Isometric knee extension strength also appeared as a better prognostic factor than other measures such as muscle mass alone or a combined score (including both muscle mass and strength/functional performance) as proposed by the European Working Group on Sarcopenia in Older People (EWGSOP). ${ }^{21}$ Thus, assessment of isometric lower-limb strength might be a simple and valid screening tool. $^{21}$

Interestingly, our results also show that - apart from knee extension strength - handgrip strength differentiates between fallers and non-fallers. The assessment of handgrip strength is arguably the most widely used ${ }^{34}$ as well as the simplest option for the evaluation of isometric strength in older adults. This test is recommended by the EWGSOP for the assessment of sarcopenia, ${ }^{10}$ and has proven to be a valid prognostic factor of different health-related outcomes including low intrinsic capacity, hospitalization risk, and overall mortality. ${ }^{35-37}$ Evidence from meta-analyses supports the validity of handgrip strength for the prediction of age-related declines in cognition, mobility, functional status and mortality in communitydwelling older people. ${ }^{38}$ Previous studies have also reported differences between fallers and non-fallers in terms of handgrip strength. ${ }^{22-24}$ Taken together, these results support the use of regular handgrip strength assessments as a simple screening tool in clinical practice, although its combination with other measures (eg, functional mobility tests) could enhance predictive accuracy. ${ }^{39}$

Limitations of this study include the short follow-up time and the non-documentation of some comorbidities that might have influenced the risk of falling such as vestibular deficits and visual or hearing impairments. Moreover, variables other than overall TUG performance and maximal strength (eg, number of steps or need for support during TUG test, rate of force development during strength tests) - that were not assessed in the present study - might have provided important information regarding the risk of falling. It must also be highlighted that, because we selected the sample size based on the results from previous studies showing significant differences between fallers and non-fallers with a similar number of study participants, no formal sample size calculation was performed; however, we cannot exclude that some differences did not reach statistical significance due to an inappropriate sample size. The present findings might not necessarily be applicable to other populations with different characteristics, such as older adults with comorbidities or those living in nursing homes. Moreover, future studies should assess whether these tests are valid for the identification of differences between single-fallers and multiple-fallers, as the low number of multiple-fallers in the present study $(\mathrm{n}=3)$ precluded this analysis. However, the major strength of this study is its prospective nature and the fact of having assessed different modalities of the TUG test and different measures of isometric strength continuously throughout the follow-up period.

\section{Conclusions}

The present study shows that isometric knee extension and handgrip strength measures can differentiate between fallers and non-fallers among older adults, these differences remaining significant even when adjusting for potential confounding factors such as age, gender, body mass index, and previous history of falls. Fallers also presented a worse performance than non-fallers on all TUG test modalities, but no differences were observed for adjusted analyses. Thus, it is concluded that isometric knee extension and in particular handgrip strength measures have the potential to serve as a simple and easy tool for detecting individuals at risk of falling as compared to functional mobility measures (ie, TUG test).

\section{Data Sharing Statement}

Data will be made available upon request to the corresponding author. Any data intended for sharing will be de-identified.

\section{Ethics Approval and Informed Consent}

The study was conducted in agreement with the Declaration of Helsinki and was approved by the Ethics Committee of the canton of Bern, Switzerland (KEK-ID: 2016-00406) and the Ethics Committee Northwestern and Central Switzerland 
EKNZ. All participants signed an informed consent form after having the procedures explained.

\section{Acknowledgments}

We would like to thank all subjects for their participation. We also extend our gratitude to everyone involved in gathering the presented data, in particular, we would like to thank Luca Persello and Manuela Wüthrich for their valuable help in data conversion.

\section{Author Contributions}

All authors made a significant contribution to the work reported, whether that is in the conception, study design, execution, acquisition of data, analysis and interpretation, or in all these areas; took part in drafting, revising or critically reviewing the article; gave final approval of the version to be published; have agreed on the journal to which the article has been submitted; and agreed to be accountable for all aspects of the work.

\section{Funding}

This study was partially funded by the University of Alcalá [Pedro L. Valenzuela, Grant FPI2016] and the Swiss Commission for Technology and Innovation (CTI) through the SWISKO project [17662.2 PFES-ES].

\section{Disclosure}

The authors declare that they have no competing interests.

\section{References}

1. World Health Organization. WHO Global Report on Falls Prevention in Older Age; 2007

2. Inouye S, Brown C, Tinetti M. Medicare nonpayment, hospital falls, and unintended consequences. $N$ Engl $J$ Med. 2009;360 (23):2390-2393. doi:10.1056/NEJMp0900963

3. Florence CS, Bergen G, Atherly A, Burns E, Stevens J, Drake C. Medical costs of fatal and nonfatal falls in older adults. $J \mathrm{Am}$ Geriatr Soc. 2018;66(4):693-698. doi:10.1111/jgs.15304

4. Rubenstein LZ. Falls in older people: epidemiology, risk factors and strategies for prevention. Age Ageing. 2006;35(SUPPL.2):37-41. doi:10.1093/ageing/afl084

5. Tinetti M, Kumar C. The patient who falls: "It's always a trade-off.". JAMA. 2010;303(3):258-266. doi:10.1001/jama.2009.2024

6. Ganz DA, Bao Y, Shekelle PG, Rubenstein LZ. Will my patient fall? $J$ Am Med Assoc. 2007;297(1):77-86. doi:10.1001/jama.297.1.77

7. Ambrose AF, Paul G, Hausdorff JM. Risk factors for falls among older adults: a review of the literature. Maturitas. 2013;75(1):51-61. doi:10.1016/j.maturitas.2013.02.009

8. Hopewell S, Adedire O, Copsey BJ, et al. Multifactorial and multiple component interventions for preventing falls in older people living in the community. Cochrane Database Syst Rev. 2018;2018:7. doi:10.1002/14651858.CD012221.pub2
9. Podsiadlo D, Richardson S. The timed "up \& go": a test of basic functional mobility for frail elderly persons. J Am Geriatr Soc. 1991;39:142-148. doi:10.1111/j.1532-5415.1991.tb01616.x

10. Cruz-Jentoft AJ, Bahat G, Bauer J, et al. Sarcopenia: revised European consensus on definition and diagnosis. Age Ageing. 2018;1:1-16. doi:10.1093/ageing/afy169

11. Kenny R, Rubenstein LZ, Tinetti M, et al. Summary of the updated american geriatrics society/british geriatrics society clinical practice guideline for prevention of falls in older persons. $J$ Am Geriatr Soc. 2011;59(1):148-157. doi:10.1111/j.1532-5415.2010.03234.x

12. Shumway-Cook A, Brauer S, Woollacott M. Predicting the probability for falls in community-dwelling older adults using the timed up \& go test. Phys Ther. 2000;80(9):896-903. doi:10.1139/z05-152

13. Kojima G, Masud T, Kendrick D, et al. Does the timed up and go test predict future falls among British community-dwelling older people? Prospective cohort study nested within a randomised controlled trial. BMC Geriatr. 2015;15(1):1-7. doi:10.1186/s12877-015-0039-7

14. Schoene D, Wu SMS, Mikolaizak AS, et al. Discriminative ability and predictive validity of the timed up and go test in identifying older people who fall: systematic review and meta-analysis. $J$ Am Geriatr Soc. 2013;61(2):202-208. doi:10.1111/jgs. 12106

15. Barry E, Galvin R, Keogh C, Horgan F, Fahey T. Is the Timed Up and Go test a useful predictor of risk of falls in community dwelling older adults: A systematic review and meta- analysis. BMC Geriatr. 2014;14(1):1-14. doi:10.1186/1471-2318-14-14

16. Beauchet O, Fantino B, Allali G, Muir SW, Annweiler C. Timed up and go test and risk of falls in older adults: a systematic review. J Nutr Heal Aging. 2011;15(10):6-11.

17. von Haehling S, Morley JE, Anker SD. An overview of sarcopenia: facts and numbers on prevalence and clinical impact. $J$ Cachexia Sarcopenia Muscle. 2010;1(2):129-133. doi:10.1007/s13539-0100014-2

18. Valenzuela P, Castillo-García A, Morales J, et al. Physical exercise in the oldest old. Compr Physiol. 2019;9(4):1281-1304.

19. Roberts HC, Denison HJ, Martin HJ, et al. A review of the measurement of grip strength in clinical and epidemiological studies: towards a standardised approach. Age Ageing. 2011;40(4):423-429. doi:10.1093/ageing/afr051

20. Mentiplay BF, Perraton LG, Bower KJ, et al. Assessment of lower limb muscle strength and power using hand-held and fixed dynamometry: a reliability and validity study. PLoS One. 2015;10(10): e0140822. doi:10.1371/journal.pone.0140822

21. Menant JC, Weber F, Lo J, et al. Strength measures are better than muscle mass measures in predicting health-related outcomes in older people: time to abandon the term sarcopenia? Osteoporos Int. 2017;28(1):59-70. doi:10.1007/s00198-016-3691-7

22. Pijnappels M, van der Burg JCE (Petra), Reeves ND, van Dieën JH. Identification of elderly fallers by muscle strength measures. Eur J Appl Physiol. 2008;102(5):585-592. doi:10.1007/s00421-0070613-6

23. Van Ancum JM, Pijnappels M, Jonkman NH, et al. Muscle mass and muscle strength are associated with pre- and post-hospitalization falls in older male inpatients: a longitudinal cohort study. BMC Geriatr. 2018;18(1):1-7. doi:10.1186/s12877-018-0812-5

24. Yang NP, Hsu NW, Lin CH, et al. Relationship between muscle strength and fall episodes among the elderly: the Yilan study, Taiwan. BMC Geriatr. 2018;18(1):1-7. doi:10.1186/s12877-0180779-2

25. Saner H, Schütz N, Botros A, et al. Potential of ambient sensor systems for early detection of health problems in older adults. Front Cardiovasc Med. 2020;7(July):1-9. doi:10.3389/fcvm.2020. 00110

26. Schütz N, Saner H, Rudin B, et al. Validity of pervasive computing based continuous physical activity assessment in community-dwelling old and oldest-old. Sci Rep. 2019;9(1):1-9. doi:10.1038/s41598-019-45733-8 
27. Gafner SC, Bastiaenen $\mathrm{CH}$, Ferrari S, et al. Hip muscle and hand-grip strength to differentiate between older fallers and non-fallers: A cross-sectional validity study. Clin Interv Aging. 2018;13:1-8. doi:10.2147/CIA.S146834

28. Chen JC, Liang CC, Chang QX. Comparison of fallers and nonfallers on four physical performance tests: a prospective cohort study of community-dwelling older Indigenous Taiwanese women. Int J Gerontol. 2018;12(1):22-26. doi:10.1016/j.ijge.2017.04.006

29. Katz S, Ford A, Moskowitz R, Jackson B, Jaffe M. Studies of illness in the aged. The index of ADL: a standardized measure of biological and psychological function. JAMA. 1963;185:914-918. doi:10.1001/ jama.1963.03060120024016

30. Nasreddine Z, Philips N, Bédirian V, et al. The Montreal Cognitive Assessment, MoCA: a brief screening tool for mild cognitive impairment. J Am Geriatr Soc. 2005;53:695-699. doi:10.1111/ j.1532-5415.2005.53221

31. Hofheinz M, Mibs M. The prognostic validity of the timed up and go test with a dual task for predicting the risk of falls in the elderly. Gerontol Geriatr Med. 2016;2:1-5. doi:10.1177/2333721416637798

32. Tang PF, Yang HJ, Peng YC, Chen HY. Motor dual-task timed up \& go test better identifies prefrailty individuals than single-task timed up \& go test. Geriatr Gerontol Int. 2015;15(2):204-210. doi:10.1111/ ggi. 12258

33. Cho KH, Bok SK, Kim YJ, Hwang SL. Effect of lower limb strength on falls and balance of the elderly. Ann Rehabil Med. 2012;36 (3):386-393. doi:10.5535/arm.2012.36.3.386
34. Bruyère $\mathrm{O}$, Beaudart $\mathrm{C}$, Reginster JY, et al. Assessment of muscle mass, muscle strength and physical performance in clinical practice: an international survey. Eur Geriatr Med. 2016;7(3):243-246. doi:10.1016/j.eurger.2015.12.009

35. García-Hermoso A, Cavero-Redondo I, Ramírez-Vélez R, et al. Muscular strength as a predictor of all-cause mortality in an apparently healthy population: a systematic review and meta-analysis of data from approximately 2 million men and women. Arch Phys Med Rehabil. 2018;99(10):2100-2113.e5. doi:10.1016/j.apmr.2018.01.008

36. Ling CHY, Taekema D, De Craen AJM, Gussekloo J, Westendorp RGJ, Maier AB. Handgrip strength and mortality in the oldest old population: the Leiden 85-plus study. CMAJ. 2010;182 (5):429-435. doi:10.1503/cmaj.091278

37. Ramírez-Vélez R, Correa-Bautista J, García-Hermoso A, Cano C, Izquierdo M. Reference values for handgrip strength and their association with intrinsic capacity domains among older adults. J Cachexia Sarcopenia Muscle. 2019;10(2):278-286.

38. Rijk JM, Roos PRKM, Deckx L, Van den Akker M, Buntinx F. Prognostic value of handgrip strength in people aged 60 years and older: a systematic review and meta-analysis. Geriatr Gerontol Int. 2016;16(1):5-20. doi:10.1111/ggi.12508

39. Wang X, Ma Y, Wang J, et al. Mobility and muscle strength together are more strongly correlated with falls in Suburb-Dwelling older Chinese. Sci Rep. 2016;6(November 2015):4-10. doi:10.1038/ srep 25420
Clinical Interventions in Aging

\section{Publish your work in this journal}

Clinical Interventions in Aging is an international, peer-reviewed journal focusing on evidence-based reports on the value or lack thereof of treatments intended to prevent or delay the onset of maladaptive correlates of aging in human beings. This journal is indexed on PubMed Central, MedLine, CAS, Scopus and the Elsevier

\section{Dovepress}

Bibliographic databases. The manuscript management system is completely online and includes a very quick and fair peer-review system, which is all easy to use. Visit http://www.dovepress.com/ testimonials.php to read real quotes from published authors. 